\title{
BMJ Open The promise of recovery: narratives of hope among homeless individuals with mental illness participating in a Housing First randomised controlled trial in Toronto, Canada
}

\author{
Maritt Kirst, ${ }^{1,2}$ Suzanne Zerger, ${ }^{1}$ Deborah Wise Harris, ${ }^{1}$ Erin Plenert, ${ }^{1}$ \\ Vicky Stergiopoulos ${ }^{1,3}$
}

To cite: Kirst M, Zerger S, Wise Harris D, et al. The promise of recovery: narratives of hope among homeless individuals with mental illness participating in a Housing First randomised controlled trial in Toronto, Canada. BMJ Open 2014;4: e004379. doi:10.1136/ bmjopen-2013-004379

- Prepublication history for this paper is available online. To view these files please visit the journal online (http://dx.doi.org/10.1136/ bmjopen-2013-004379).

Received 1 November 2013 Revised 7 January 2014 Accepted 31 January 2014

CrossMark

\footnotetext{
${ }^{1}$ Centre for Research on Inner City Health, Keenan Research Centre in the Li Ka Shing Knowledge Institute, St. Michael's Hospital, Toronto, Ontario, Canada ${ }^{2}$ Dalla Lana School of Public Health, University of Toronto, Toronto, Ontario, Canada ${ }^{3}$ Department of Psychiatry, University of Toronto, Toronto, Ontario, Canada
}

Correspondence to Dr Maritt Kirst; kirstm@smh.ca

\section{ABSTRACT}

Objectives: Hope is widely embraced as an important factor in the recovery process. The role of housing in inspiring hope and facilitating recovery has been explored with homeless populations but is not well understood. This study explores perspectives on hopes for recovery and the role of housing on these hopes from the perspective of homeless adults experiencing mental illness participating in a multisite Housing First randomised controlled trial in Canada. The study draws on data from in-depth qualitative interviews with participants from the Toronto, Ontario site of the 'At Home/Chez Soi' Project.

Design: In-depth interviews were conducted with a subsample of participants from a larger Housing First randomised controlled trial.

Setting: The research took place in Toronto, Canada. Participants: 60 participants in the larger trial (36 from the Housing First group and 24 from the Treatment as Usual group) took part in in-depth interviews.

Method: Participants for the in-depth interviews were purposively selected from the larger trial sample in Toronto and participated in an interview at the beginning of the study (baseline). Data from the baseline interviews were analysed using the constant comparative method derived from grounded theory methods.

Results: Participants' narratives show clear visualisation of goals for recovery, and emphasise that housing is an integral factor that can facilitate hope and support dimensions of recovery. However, some participants had difficulty adjusting to housing, and were concerned about feeling socially isolated, which could have negative implications for hopefulness and recovery.

Conclusions: Housing First interventions should explicitly incorporate hope-inspiring, recovery-oriented approaches and support participants while adjusting to housing in order to sustain hopefulness.

\section{INTRODUCTION}

Homelessness is a growing problem in Canada, with approximately 200000 individuals

\section{Strengths and limitations of this study}

- Limitations of the study include that these findings reflect the experiences of individuals experiencing homelessness and mental health issues at one point in time.

- Findings emerged from a large sample embedded within a larger randomised controlled trial. Findings contribute to existing research in this area by highlighting that housing can activate the mechanism of hope, through which recovery for individuals experiencing homelessness and mental illness can be pursued.

- The study has emphasised that given the important role of hope, Housing First and other housing programmes need to explicitly integrate hope-inspiring, recovery-oriented approaches.

experiencing homelessness each year. ${ }^{1}$ In Toronto, Canada's largest city, the estimated homeless population has grown from 4969 in 2006 to 5219 in $2013 .^{2}$ Research has shown that the prevalence of mental health and substance use problems is higher among homeless individuals than in the general population, and that homeless individuals often have complex service needs. ${ }^{3}{ }^{45}$ As a result, interventions that transition homeless individuals with serious mental health issues into housing and support their complex mental health needs have been developed and implemented, primarily in the USA. ${ }^{36}$

Related to prior histories of trauma, loss, illness and impoverishment that are often prevalent among homeless individuals with serious mental health issues, this population often experiences a loss of hope. ${ }^{7}$ Hope has been called the 'bedrock' of recovery, defined as how people 'manage their mental illness and/or addiction and their residual 
effects to claim or reclaim their lives in the community'. ${ }^{9}$ The current Canadian Mental Health Strategy identifies hope as one of the key principles on which recovery is built, ${ }^{10}$ and the US Substance Abuse and Mental Health Services Administration's new definition of recovery from mental illness and substance use disorders calls hope the catalyst of the recovery process. ${ }^{11}$

While widely embraced for its role as both a trigger and a 'maintaining factor' in the recovery process, hope remains a difficult concept when translating into strategies and interventions. A recent systematic review of recovery literature named hope and optimism about the future as one of the dimensions of the recovery process with the most "proximal relevance to clinical research and practice' (ref. 12, p. 449), yet development of interventions that mental health clinicians can employ to rekindle and sustain hope for persons in recovery is in early stages. For example, researchers reviewing hopeinspiring interventions for people with mental illness identified numerous recovery-oriented interventions with hope as a secondary outcome, but indicated that no successful interventions specifically focused on increasing hope. ${ }^{13}$ These authors concluded that interventions with the greatest impact on increasing hope relied on multidimensional hope concepts, and those narrowly focused-such as only on goal setting and achievement-were ineffective. They also identified five promising elements for inclusion in interventions: (1) collaborative strategies for illness management, (2) focus on fostering relationships with service providers and others outside the mental health system; (3) facilitating peer connections and support; (4) helping clients form and pursue realistic goals and (5) supporting multiple positive factors such as self-esteem, self-efficacy, spirituality and well-being, identifying this last element as the one most neglected in clinical practice. ${ }^{13}$

\section{Homelessness and hope}

Homelessness interferes with these and other elements key to recovery: for example, it complicates illness management and medication maintenance, erodes selfcontrol and self-esteem and engenders mistrust and selfisolation. ${ }^{14}{ }^{15}$ Indeed, some have declared homelessness 'the antithesis of recovery' (ref. 16, p. 69). Qualitative studies which have studied hope with persons experiencing homelessness, including children, street youth, women and families, veterans and shelter residents, all share the common theme that powerlessness associated with the experience of homelessness has a destructive impact on self-esteem and hope. ${ }^{74} 15{ }^{17-19}$ An interesting exception to this was one of the few quantitative studies measuring hope with homeless persons, in this case participants in a consumer-run mental health services programme, which found a positive association between homelessness and hope. ${ }^{20}$ While all of these researchers agree that development of hope-inspiring interventions that address the complexity of homelessness is important and possible, and some progress has been made with homeless women and families, the 'how' of inspiring hope remains elusive-especially for single, chronically homeless adults. ${ }^{21-23}$

\section{The role of housing}

The role of housing in inspiring hope and facilitating recovery has been explored with homeless populations, though it is not well understood. 'Housing First' is an intervention for individuals experiencing homelessness and mental illness which places individuals into permanent independent Housing First-without prerequisites for sobriety and treatment-and offers flexible access to supportive health services. ${ }^{24}$ Research on this intervention has consistently found that placing individuals in housing first does not negatively affect ability to maintain housing, has no deleterious effects on recovery and has led to improved mental health outcomes. ${ }^{25}{ }^{26}$ While housing creates critical stability to facilitate the recovery process, its role and importance are otherwise unclear; one qualitative study found that newly housed Housing First participants only 'partially attained' core elements of recovery, including hope and social connections, once housed. $^{27}$

This study contributes to this body of literature by exploring the importance of housing to hopes for recovery from the perspective of chronically homeless adults with mental illness. The study draws on data from in-depth qualitative interviews with participants from the Toronto, Ontario site of the multisite 'At Home/Chez Soi' Project in Canada.

\section{METHODS}

The 'At Home/Chez Soi' study is a randomised controlled trial (RCT) that evaluates the effectiveness of a 'Housing First' approach in improving the lives of individuals who experience both homelessness and mental illness. The project was implemented across five cities in Canada-Moncton, Montreal, Toronto, Winnipeg and Vancouver-and received federal funding for 4 years.

'At Home/Chez Soi' project participants in Toronto were randomised to one of two Housing First interventions based on the level of mental health service need, or to a 'Treatment as Usual' arm. High needs participants $(\mathrm{N}=197)$ were randomised to an Assertive Community Treatment (ACT) arm or Treatment as Usual, while moderate needs participants $(\mathrm{N}=378)$ were randomised to an Intensive Case Management (ICM) arm or Treatment as Usual. Moderate needs participants who identified as ethnoracial and were randomised to the intervention were further provided with the option to participate in an ethnoracial-intensive case management intervention (ER-ICM; specific to the Toronto site of the project). Participants in the Housing First interventions received a rent supplement and housing of their choice, and mental health service supports according to their level of need. Participants in the 'Treatment as Usual' arm received information materials about 
services available in the community but no direct services. Study participants were classified as those with high needs or moderate needs using an algorithm described in Goering et $a l^{3}$ that draws on Section 3 of the Ontario Standards for ACT teams.

Participants completed a series of surveys at specific time intervals to assess the effects of the housing first intervention on such outcomes as mental health, substance use, social functioning, community integration and criminal justice system involvement. A subsample of 60 participants took part in in-depth qualitative interviews at the beginning of the study (baseline).

\section{Data collection}

Participants in the baseline qualitative interviews were selected from the larger RCT sample by sampling every 10th participant randomised to each study arm. This approach was taken to facilitate sampling across the larger RCT sample. Purposive sampling was also employed in order to achieve representation across gender and ethnicity. Eighty-three participants were invited to participate in the interview by the study recruitment staff, and 23 participants either declined to participate or it was not possible to schedule an interview with them. Sixty participants agreed to participate, and interviews were conducted with 36 participants from the Intervention group (12 from the ACT intervention, 12 from the ICM and 12 from the ER-ICM intervention) and 24 from the Treatment as Usual group (12 with high needs and 12 with moderate needs). Interviews were conducted by three research staff, including a peer researcher, with training in conducting in-depth interviews, between March 2010 and June 2011. All participants provided written, informed consent to participate, and agreed to have the interviews audio-recorded. Interviews were semistructured, and asked questions on history of homelessness and mental health issues, daily activities, experiences with mental health and social services, and hopes for the future. Interviews took place in a location that was convenient for the participant, typically the project office, and ranged from approximately $45 \mathrm{~min}$ to $1.5 \mathrm{~h}$ in length. Interview participants were also asked to complete a brief demographic form, and each received an honorarium of $\$ 25$, two transit tokens and a resources sheet outlining health and social services in the Toronto area.

\section{Data analysis}

Qualitative interview data were analysed with a coding process involving the constant comparative technique derived from grounded theory methods. ${ }^{28}$ Sensitising questions regarding hope for the future and the related role of housing in hopes for the future guided the coding process. ${ }^{29}$ Data were coded into common categories based on similar content, and then emerging categories were compared with previous categories. The analysts then transformed codes into higher level categories by analysing and grouping similar codes into conceptual categories, using the constant comparative method of analysis. ${ }^{29}$ Eventually, broader categories were reduced to a set of higher level themes. To ensure reliability during this process, the analysts double-coded six interview transcripts, and met regularly to compare the accuracy of their codes and worked by consensus to refine discrepancies. There was a high degree of consensus in the coding, with slight differences in the wording of codes. Discrepancies in coding were discussed and resolved in consultation with the original interviewer and a qualitative research supervisor. Descriptive statistics were calculated on the demographic data using SAS software.

\section{RESULTS}

\section{Sample characteristics}

Demographic information for the study sample is presented in table 1. Sixty-seven per cent of participants were men, $30 \%$ were women and $2 \%$ identified themselves as transgender. Fifty-five per cent of participants identified themselves as members of an ethnoracial group, and 7\% identified themselves as Aboriginal. Mean participant age was 41 years. Thirteen per cent of participants completed grade 8 or less, and $37 \%$ had not completed high school. Twelve per cent of participants reported having been homeless for 6 months or less, and 32\% reported having been homeless for six or more years. Forty per cent of participants were identified as having a high need level, and $60 \%$ were identified as having moderate needs.

\begin{tabular}{lc} 
Table 1 Sample demographics $(\mathrm{N}=60)$ & \\
\hline & Per cent \\
\hline Gender & 67 \\
Male & 30 \\
Female & 2 \\
Transgender & 2 \\
Not indicated & \\
Ethnoracial & 55 \\
Yes & 45 \\
No & 41 \\
Age (mean) & 3 \\
Education level & 14 \\
Completed graduate school & \\
Completed university or business, trade, \\
technical school & 11 \\
Some university or business, trade, technical \\
school & \\
Completed high school & 22 \\
Some high school, not completed & 37 \\
Completed grade 8 or less & 13 \\
Months homeless in lifetime & 15 \\
$\leq 6$ & 32 \\
$7-11$ & 32 \\
$12-23$ & \\
$24-71$ & \\
$\geq 72$ & \\
\hline &
\end{tabular}


Thirty study participants in the intervention arms were newly housed through the 'At Home/Chez Soi' project at the time of the baseline in-depth interview, while five intervention participants were still waiting to be housed through the project. At the time of the interview, 11 study participants who had been randomised into the Treatment As Usual arm had obtained housing independently of the project through the private market or through various social housing organisations in the city. Thus, participants were either newly housed (within a month or two) through the project or independently, were about to receive housing through the project or were aspiring to become housed (unhoused TAU participants), and were reflecting on hopes for the future as well as anticipated benefits and challenges associated with being housed. As a result, we do not treat TAU participants as an explicit comparison group in the analysis.

\section{Hopes for recovery}

Many participants had a vision for recovery and hoped to make life changes as part of this process. For a number of participants, recovery was associated with the idea of starting over. For one participant in particular, being randomised to the intervention group in the "At Home/Chez Soi' project was an opportunity to begin a new life:

I've lived a very rough life but I've made it, I am here today to say that this program has helped me in so many ways of my life...a turning point where I don't have to think about drugs and I don't have to think about being homeless, I don't have to think about anything but positive things from now on. Like I had doubts when I first came even when I got accepted but when I see everything happening according to the way they said it would, I was like this is the start of a new life for me. (Female participant, ACT, housed)

A number of participants expressed wanting to experience personal growth. One participant discussed the desire to feel proud of himself again:

I want to be proud of me. I used to be really proud of me, I'm not all that proud of me right now. (Male participant, ER-ICM, unhoused).

For many, dealing with substance use problems facilitated the recovery process. Without 'getting clean', some participants felt that recovery and finding stability in life would not be possible:

There's a lot of people out there who would like to...get the help that I have gotten, right? But then due to this... addiction, a lot of them [are]... going to ruin it. (Male participant, ER-ICM, housed).

Some also hoped to achieve self-acceptance as part of the recovery process. This participant explained that recovery involved accepting past experiences and finding self-worth:
I guess part of that [recovery] would be to...learn to at least like myself or not hate myself um,...try and get well you know, trying to understand the different emotions about what happened in the past like you know, guilt or...and, and whatever all that, all those different emotions that come up from that... and being able to see some you know, like some worth in life. (Female participant, TAU, unhoused)

However, some participants discussed the barriers that they would need to overcome in order to establish the kind of life they would like for themselves:

I hope that maybe one day I will get healed, I won't have to take medications anymore [...] I wouldn't have to be drowsy and I can do what I want, get a job, you know? And fulfill my dreams. (Female participant, ACT, housed)

\section{Hope and personal goal-setting}

A number of participants expressed hope for future recovery through personal goal-setting. Goals included seeking education, employment and rebuilding relationships in the future. Many discussed wanting to get a job or to establish a career, as a way to support their future and to rebuild their self-esteem.

Returning to school or pursuing further education and training was also an important aspect of participants' vision for their future:

I have to prove to myself that I could have been who I wanted to be. I am going to get my Grade 12 and I am going to take my nursing course... (Female participant, ACT, housed)

Many participants discussed the desire to develop or re-establish positive, healthy relationships. Some hoped that they might meet a romantic partner, and discussed wanting to get married and have a family:

I still want to get married. I still want to have another child. I still want to live. Female participant, ICM, housed)

Other participants were more focused on rebuilding relationships that were lost or damaged during their time while homeless.

Housing as a condition for realisation of hope for future recovery - anticipated and experienced benefits

Housing as the first step

Despite having well-defined hopes for future recovery, for most participants, becoming housed was key to the realisation of these hopes. Many participants saw becoming housed as the first step in a move towards rebuilding their lives and addressing broader notions of recovery:

A place to live and then from there I can start doing my things, like getting better and going out. Getting into a routine. Finding a job, getting the training for something else. (Male participant, TAU, unhoused) 
Once I get an apartment and I see this doctor tomorrow I know this doctor is going to prescribe the right medication because my other doctor she is going to recommend what I need... and once I get an apartment I, I will go to the food bank, I will go buy groceries... As soon as I get an apartment I recover, I stop... I don't want to know nobody... I don't even want to have a cigarette inside. I just want to go outside and do my own thing... I might go back to work. (Male participant, ACT, housed)

Several participants associated stable housing with an increased sense of security, peace of mind and a decreased stress level, which in turn would allow them to focus on other life domains:

[The housing is] there for a couple of years so ... it lends a little stability at least to your life for a short period of time and enables you to get some things done...Because when you've been through the shelter system as I have, you realize the value of stability...(Female participant, ER-ICM, housed)

\section{Anticipated independence and control associated with housing}

Many participants anticipated a sense of independence and control associated with living on their own-especially after living on the streets or in a shelter:

Home to me is the best, it's your home, you own everything that's in there, you have your own key, you have your freedom to go in and out, you know? You have your own shower, you can cook, you can do whatever in there. (Female participant, ER-ICM, housed)

The door key, as a symbol of this independence, was described by a number of participants:

I pray every day that I would get somewhere to go on my own again, you know? That I can put my own key and turn it myself. (Male participant, ER-ICM, unhoused)

For many participants, having their own key represented a renewed sense of freedom and self-reliancesomething they had not felt while they were homeless. As one participant explained:

Home is like your own place, your own rules, you know? You wake up and [...] you can do whatever you want, no one can tell you anything because it's your own place. (Male participant, ICM, housed)

A number of participants who were newly housed discussed feeling more independent and self-sufficient, and generally having more control over their lives:

Now at least I can clean my house the way I want it $[\ldots]$ That's important to me, I can run my house the way I want it. (Female participant, ER-ICM, housed)

Several participants discussed that an important part of maintaining stable housing was the ability to pay their rent regularly and on time. One participant described the ability to pay his own rent as a symbol of self-worth and self-sufficiency:

I want to be able to pay my own rent that's what I want to change, I want to get a job and pay my own rent, man. Feel like a somebody, you know? Right now I don't feel like a somebody, you know? I don't. (Male participant, ER-ICM, housed)

\section{Anticipated benefits of housing on health and well-being}

A sense of control and security anticipated to accompany housing was also central to the achievement of other hopes, for example, improvements to health and well-being. Many participants felt that their physical and mental health would improve with the security and stability that comes with housing:

Well, it [recovery] means having as few mania attacks as possible I don't think they'll stop entirely ever, having a few depression attacks as possible. Certainly getting my physical health back which is happening now because... I think mostly recovery has to do strangely enough with having permanent subsidized housing... (Female participant, ER-ICM, housed)

For a number of participants in the intervention arms, the most significant shift related to moving from homelessness to housing was perceived to be the ability to stay in during the day and care for their health, as opposed to having to be out on the streets during the day in accordance with shelter policies. One participant who was housed at the time of the interview noted an immediate effect on his physical health:

I feel a lot better because I don't have to go running [...] When I got kicked out (of the shelter) I had to walk around and it was really hard on my knees and feet. So it's a lot better now. (Male participant, ACT, housed)

Lack of sleep while homeless was another important factor that many participants discussed as negatively affecting their physical health. With stable housing, participants felt that they would be able to get better, more consistent rest and engage in self-care. Another participant in the intervention group discussed the impact of being housed on his overall well-being:

I feel different, you know? I feel more, more together, yeah. I sleep until sometimes 9:30, 10 o'clock. And I'm like, 'Oh my God, this is great. I can actually sleep!' (Male participant, ER-ICM, housed)

This participant described that housing contributed to improved emotional well-being and facilitated hopes for the future:

But in terms of emotional, you know, it's been a month...right now, I feel a lot better. I'm feeling better, you know? It is really that, thanks to this program, 
I think, uh...I start to...I'm starting to calculate and saying, You know what? I think this is where I'd like to see myself some time, you know? I want to be here. I don't want to go back out there.

For some study participants, access to a proper kitchen, the ability to cook their own food and eat when they were hungry represented important health and nutritional benefits, in addition to providing welcome control and freedom.

\section{Housing as a precursor for relationship rebuilding}

A number of participants hoped to re-establish relationships once they were in stable housing. One participant talked about how difficult it was to maintain relationships with his family while he was living on the streets:

When you're out there, you don't have a family. You can't [...] Where are you going to receive them? Who wants a person who hasn't taken a shower for three or four days? (Male participant, ER-ICM, housed)

Newly housed, this participant was proud to invite his brother over and could now take the first step towards rebuilding this relationship:

I have a place where I can receive him. That's an important thing. So I can have a family again.

Stable housing also allowed a number of participants to regain or maintain relationships with their children. One participant spoke about her sons not being able to visit her when she was living in a shelter. Now housed, one of her sons is living with her and another son is able to visit whenever he likes. Others indicated the importance of being able to open up their homes to friends and potential romantic partners, something that they were previously unable to do while homeless, either due to shelter rules or out of embarrassment. A number of participants also discussed valuing the companionship of pets, and four expressed the desire to get a companion animal once housed. However, some expressed concern about their ability to have a pet while housed due to regulations preventing pet ownership in apartment buildings:

They [dogs] go into shelters and then they're euthanized or whatever, like you've got to find room for people with dogs because they're a companion and Louis was with... my dog's named Louis, he was with me when I went through... I didn't tell you all my illnesses... (Female participant, TAU, housed)

\section{Concerns about housing: issues that may temper the benefits}

While most participants in the intervention arms of the project discussed the benefits of being housed, there was some concern around being isolated in their apartments and the potential effect this could have on their recovery:
So... I am excited but I am nervous, you know? Because I am institutionalized now, I have been in a shelter for 3 years, there is a lot of things I haven't had to do for myself you know? And I... am a little worried about the isolation so I am going to have [to] like take steps towards not being isolated, you know? (Female participant, ICM, housed)

One participant who had recently been housed noted a negative effect of being housed on his mental health:

I don't do very much anymore. I have been staying right in my apartment. I haven't been feeling good, like, mentally I guess you can say. (Male participant, ICM, housed)

Another participant in one of the intervention arms who had recently been housed discussed not yet feeling comfortable in his new home due to the drastic shift from being surrounded by other people in a shelter or in jail, to living alone:

Even if I am in jail, I am not alone ... there is nothing wrong with the house, you know, it's me, I have to change that thinking. (Male participant, ACT, housed)

At times, living alone was so overwhelming for this participant that he considered giving up the apartment and leaving town.

On the basis of previous experiences with destructive relationships, several participants discussed being very selective about who they would invite over-if anyone at all-in order to maintain their current housing and limit the potential for any disturbances. As one participant said:

A few guys pop over but there is only a select few that know where I live. I like to keep it that way. (Male participant, ICM, housed).

Overall, it was invaluable for many participants to be able to choose when and how much time they would spend with others, but this was another contributing factor to feelings of social isolation for some participants.

\section{DISCUSSION AND CONCLUSION}

Study findings reflect that participants show considerable hope and optimism for recovery in the future. This hope was manifested in key self-management strategies of goalsetting, rebuilding self-esteem and finding meaning through relationships and symbolism (eg, the door key). ${ }^{13}$ Specifically, participants' perceptions of recovery are focused on hopes to regain control over their lives and a sense of independence after a period of powerlessness, which would facilitate achieving self-acceptance, rebuilding and developing new relationships, as well as help them to reclaim their lives in the community. These findings regarding hope for future recovery echo results from other research in this area. ${ }^{30-32}$

Participants' narratives show clear visualisation of the role of housing in implementing these strategies, and 
emphasise that housing is an integral factor that can facilitate hope and support dimensions of recovery. The majority felt that achieving the aforementioned dimensions of recovery was dependent on housing, as a stable roof over their heads would alleviate the need to focus on survival concerns, and this combined with an anticipated increased sense of independence and security that housing would bring, would provide them with the opportunity to instead concentrate on their recoveryoriented goals. This study further confirms that housing is an important foundation from which to build and act on hope, providing participants with hopes for experiences of control, independence and security and an opportunity to sleep, reflect and care for their physical and mental health. These findings support the notion of increased ontological security, reflecting an increased sense of security, safety and predictability that can be enhanced by permanent housing, which has been noted in research on Housing First interventions with homeless individuals with serious mental illness. ${ }^{27} 31$ These findings expand on this research by connecting the importance of increased ontological security to hopebuilding and recovery processes in that the receipt of actual, but also anticipated housing, can stimulate a sense of ontological security which can further build and support action on hope, a key component in the recovery process. ${ }^{12} 1327$

The study also reveals some critical areas in which housing alone is not sufficient for recovery, but could be strongly bolstered by interventions expressly aimed at building and acting on hope. The Housing First model lays emphasis on positive relationships with service providers and client-driven goal-setting, which are elements already known to be important bases for successful hope-building interventions, ${ }^{13}$ and this study identifies areas of focus with the greatest potential. For example, many of these participants considered housing an opportunity to repair lost or damaged relationships, and to build new healthy relationships, but were not always clear on how to actualise those hopes. While many participants desired to reduce or cease harmful substance use behaviours, and saw control over their housing as key, they needed help to overcome the social isolation that resulted from their turning away friends previously associated with substance use.

Study limitations include that these findings reflect point-in-time observations and do not explore perceived long-term impacts of housing on hopefulness and recovery trajectories among study participants. However, longitudinal analysis of the data in this area is currently ongoing.

Overall, these findings contribute to existing research in this area by showing how hope, housing and recovery are connected in a large sample of homeless individuals experiencing mental illness participating in a Housing First RCT. Specifically, findings support that anticipated and actual housing, facilitated through the mechanism of Housing First programmes that provide housing and supports to this population, can foster hope for increased ontological security and achievement of other recovery-oriented goals. ${ }^{27}$ However, housing alone is not sufficient to foster hope and support this population in moving forward in the recovery journey. In order to support the hope that is inspired by such interventions, these programmes need to focus on assisting clients during the adjustment period while becoming newly housed to prevent and address social isolation. Furthermore, these programmes should explicitly integrate hope-inspiring, recovery-oriented approaches, ${ }^{13}$ such as goal-setting, finding meaning and implementing strategies to manage illness, build self-esteem and (re) develop relationships.

Acknowledgements We thank all study participants who shared their stories with us, and we thank the local qualitative research team. We also thank Jayne Barker (2008-11), Cameron Keller (2011-12), and Catharine Hume (2012-present) Mental Health Commission of Canada At Home/Chez Soi National Project Leads, Paula Goering, the National Research Lead, the National Research Team, the five site research teams, the Site Co-ordinators, and the numerous service and housing providers, as well as persons with lived experience, who have contributed to this project and the research.

Contributors MK and SZ drafted the manuscript. MK oversaw the data collection and contributed to the analysis; DWH and EP conducted the interviews and data analysis and drafted the thematic sections. VS supervised the research and critically reviewed the manuscript.

Funding This research was made possible through a financial contribution by Health Canada and funded by the Mental Health Commission of Canada. The views expressed solely represent those of the authors.

\section{Competing interests None.}

Ethics approval The study was approved by St Michael's Hospital Ethics Review Board.

Provenance and peer review Not commissioned; externally peer reviewed.

Data sharing statement No additional data are available.

Open Access This is an Open Access article distributed in accordance with the Creative Commons Attribution Non Commercial (CC BY-NC 3.0) license, which permits others to distribute, remix, adapt, build upon this work noncommercially, and license their derivative works on different terms, provided the original work is properly cited and the use is non-commercial. See: http:// creativecommons.org/licenses/by-nc/3.0/

\section{REFERENCES}

1. Gaetz S, Donaldson J, Richter T, et al. The state of homelessness in Canada 2013. Toronto: Canadian Homelessness Research Network Press, 2013.

2. Toronto Shelter Support and Housing Administration. 2013 Stree Needs Assessment: Interim Report, Toronto: City of Toronto Shelter Support and Housing Administration, 2013.

3. Goering PN, Streiner DL, Adair C, et al. The At Home/Chez Soi trial protocol: a pragmatic, multi-site, randomised controlled trial of a Housing First intervention for homeless individuals with mental illness in five Canadian cities. BMJ Open 2011;1:e000323

4. Fischer PJ, Breakey WR. Homelessness and mental health: an overview. Int J Ment Health 1986;14:6-41.

5. Padgett DK, Struening EL, Andrews $H$. Factors affecting the use of medical, mental health, alcohol and drug treatment services by homeless adults. Med Care 1990;28:805-21.

6. Nelson G, Hall GB, Forchuk C. Current and preferred housing of psychiatric consumers/survivors. Can J Community Ment Health 2003;22:5-19.

7. Tollett $\mathrm{JH}$, Thomas SP. A theory-based nursing intervention to instill hope in homeless veterans. Adv Nurs Sci 1995;18:76-90.

8. Cutcliffe JR, Zinck K. Hope maintenance in people living long-term with HIV/AIDS. Qual Res J 2011;11:34-50. 
9. Davidson L, White W. The concept of recovery as an organizing principle for integrating mental health and addiction services. J Behav Health Serv Res 2007;34:109-20.

10. Mental Health Commission of Canada. Changing directions, changing lives: the mental health strategy for Canada. Mental Health Commission of Canada, 2012.

11. SAMHSA. SAMHSA's working definition of recovery from mental health and substance use disorders. Substance Abuse and Mental Health Services Administration 2012.

12. Leamy M, Bird V, Le Boutillier C, et al. Conceptual framework for personal recovery in mental health: systematic review and narrative synthesis. Br J Psychiatry 2011;199:445-52.

13. Schrank B, Bird V, Rudnick A, et al. Determinants, self-management strategies and interventions for hope in people with mental disorders: systematic search and narrative review. Soc Sci Med 2012;74:554-64.

14. Partis M. Hope in homeless people: a phenomenological study. Prim Health Care Res Dev 2003:4:9-19.

15. Williams S, Stickley T. Stories from the streets: people's experiences of homelessness. J Psychiatr Ment Health Nurs 2011;18:432-9.

16. Kirkpatrick $\mathrm{H}$, Byrne $\mathrm{C}$. A narrative inquiry: moving on from homelessness for individuals with a major mental illness. J Psychiatr Ment Health Nurs 2009;16:68-75.

17. Hughes JR, et al. Youth homelessness: the relationships among mental health, hope, and service satisfaction. J Can Acad Child Adolesc Psychiatry 2010;19:274-83.

18. Herth K. Hope as seen through the eyes of homeless children. J Adv Nurs 1998;28:1053-62.

19. Berman $\mathrm{H}$, Mulcahy GA, Forchuk $\mathrm{C}$, et al. Uprooted and displaced: a critical narrative study of homeless, aboriginal, and newcomer girls in Canada. Issues Ment Health Nurs 2009;30:418-30.

20. Hodges JQ, Hardiman ER, Segal SP. Predictors of hope among members of mental health self-help agencies. Soc Work Mental Health 2004;2:1-16.

21. Boydell KM, Goering P, Morrell-Bellai TL. Narratives of identity: re-presentation of self in people who are homeless. Qual Health Res 2000;10:26-38.
22. Herth K. Hope from the perspective of homeless families. J Adv Nurs 1996;24:743-53.

23. Finfgeld-Connett D, Bloom TL, Johnson ED. Perceived competency and resolution of homelessness among women with substance abuse problems. Qual Health Res 2012;22: $416-27$.

24. Stefancic A, Tsemberis S. Housing first for long-term shelter dwellers with psychiatric disabilities in a suburban county: a four-year study of housing access and retention. J Prim Prev 2007;28:265-79.

25. Greenwood RM, Schaefer-McDaniel NJ, Winkel G, et al. Decreasing psychiatric symptoms by increasing choice in services for adults with histories of homelessness. Am J Community Psychol 2005;36:223-38.

26. Tsemberis $\mathrm{S}$, Kent $\mathrm{D}$, Respress $\mathrm{C}$. Housing stability and recovery among chronically homeless persons with co-occurring disorders in Washington, DC. Am J Public Health 2012;102:13-16.

27. Padgett DK. There's no place like (a) home: ontological security among persons with serious mental illness in the United States. Soc Sci Med 2007;64:1925-36.

28. Glaser BG, Strauss A. The discovery of grounded theory: strategies for qualitative research. New York: Aldine de Gruyter, 1967.

29. Charmaz K. Discovering chronic illness: using grounded theory Soc Sci Med 1990;30:1161-72.

30. Padgett DK, Henwood B, Abrams C, et al. Social relationships among persons who have experienced serious mental illness, substance abuse and homelessness: implications for recovery. Am J Orthopsychiatry 2008;78:333-9.

31. Henwood BF, Hsu H-T, Dent D, et al. Transitioning from homelessness: a 'fresh start' event. J Soc Soc Work Res 2013;4:47-57.

32. Padgett DK, Henwood BF. Qualitative research for and in practice: findings from studies with homeless adults who have serious mental illness and co-occurring substance abuse. Clin Soc Work $J$ 2012;40:187-93. 